\title{
Power Limitation at High Wind Speed for a Variable Speed Fixed Pitch Wind Turbine using Close-Loop Scalar Control
}

\author{
N.Rosmin ${ }^{1}$, S.J.Watson ${ }^{2}$ and M.Tompson ${ }^{3}$ \\ 1,2,3 Department of Electronics and Electrical Engineering \\ Loughborough University \\ LE11 3TU Loughborough, Leicestershire (United Kingdom) \\ Phone/Fax number:+0044 1509 635343, e-mail: N.Rosmin@Lboro.ac.uk, S.J.Watson@Lboro.ac.uk, \\ M.Tompson@Lboro.ac.uk \\ ${ }^{1}$ Faculty of Electrical Engineering, \\ Universiti Teknologi Malaysia, \\ 81310 Skudai, Johor, Malaysia \\ Phone/Fax number: +0060 75535329, e-mail: Norzanah@fke.utm.my
}

\begin{abstract}
This paper represents the speed regulation for a fixed pitch stall-regulated variable speed wind energy conversion system. The speed regulation in the high (above rated) wind speeds region is the main topic of this paper where in this region, the rotor/generator speed activity is controlled by using the concept of adjustable or variable speed drive (ASD/VSD). Speeds need to be controlled in order to maintain the generated power by reducing the power coefficient from the peak of Cp curve. It can be achieved by reducing the tip speed ratio from the optimum value when wind speed vary from rated wind speed to cut-out wind speed. Therefore, closed-loop scalar speed control with the concept of constant ratio of voltage/frequency was being applied. In addition, simple algorithms of drive train and squirrel cage induction generator were being used. A proportional integral (PI) controller was used to control the generator slip speed. Results demonstrate that such a closed-loop scalar control with proportional integral (PI) controller is good enough to accurately maintain constant power by restraining the rotational speed corresponding to the wind speed variation at the rated wind speed.
\end{abstract}

\section{Key words}

Variable speed, stall-regulated, fixed pitch, power limitation.

\section{Introduction}

In general, a variable speed wind turbine has 3 main different operating regions: below, intermediate and above wind speed [1] as illustrated in Figure 1.

In a fixed pitch, variable speed, stall-regulated wind turbine, maximum power regulation below rated wind speed is regulated by changing the rotor/generator speed at large frequency range [2]. In such a turbine, capturing the power at a maximum value is obtained by keeping the power coefficient $(\mathrm{Cp})$ at maximum peak point by maintaining the tip speed ratio $(\lambda)$ at its optimum value [3].

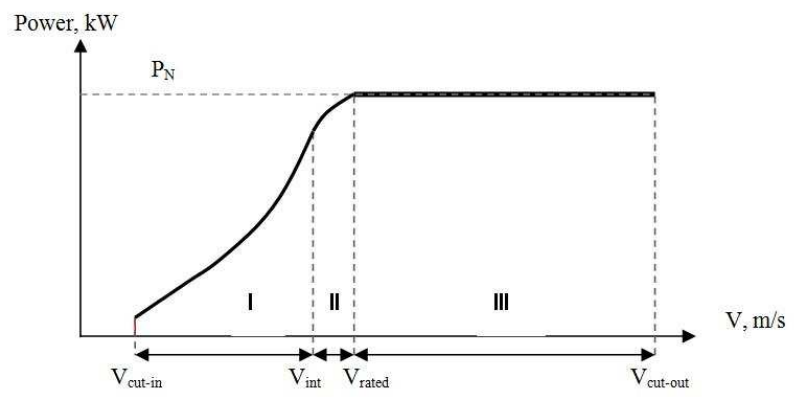

Figure 1: Control strategy at different regions

In intermediate region or intermediate wind speed, turbine runs at fixed speed. Then, in high wind speed region, turbine runs at a fixed speed as in conventional strategy. But as an alternative, they are designed to run at variable speed whereby the power coefficient needs to be reduced by reducing the rotor/generator speed [4]. In the early market, wind industry was predominated by stall regulated fixed speed wind turbines. However, new innovations have resulted in the improvement of turbine's reliability. Even though stall regulated fixed pitch wind turbine offers the cheapest cost among the existed wind turbines in the market, its problems including noise, severe vibrations, high thrust loads and low power efficiency. Therefore, a new alternative of control needs to be initiated. Hence, to improve such drawbacks, the rotation of the rotor speed is made flexible where rotation can be controlled in variable speed.

Hence, the objective of this paper is to develop a simulation model which represents the behavior of stall regulated variable speed wind turbine at high wind speed 
control region by using the closed loop scalar control with adjustable speed drive concept. This paper is organized as follows. Section 2 consists of the description of each sub-model in wind turbine system while section 3 describes the scalar control of induction machine. Then, Section 4 shows experimental results and lastly, some conclusions are given in Chapter 5.

\section{Model Description}

Figure 2 shows the Simulink model that was developed to simulate a stall-regulated, variable-speed, wind turbine system. This turbine comprises 4 submodels named wind speed, aerodynamic, drive train and squirrel cage induction generator model.

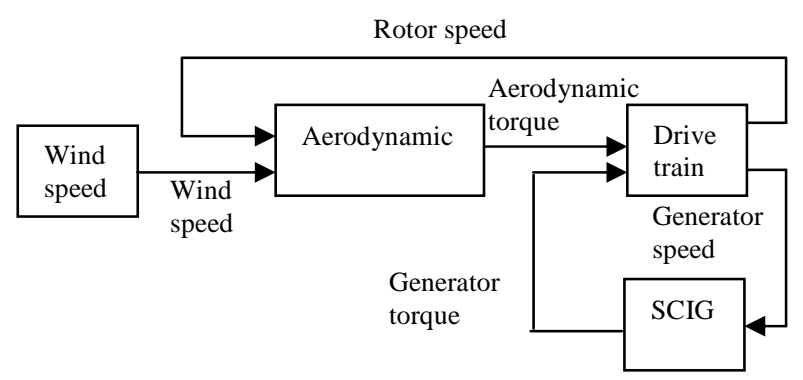

Figure 2: Structure of wind turbine system

\section{A. Wind Speed Model}

Wind speed is considered as a disturbance in the wind turbine model. In this work, the wind speed time series is modelled by using actual wind speed data which was recorded in West Beacon farm, loughborough.

\section{B. Aerodynamic Model}

Aerodynamic model represents the interaction between turbine and the wind stream. The performance of useful mechanical power in the wind is greatly depended on the blade profile. The efficiency of power extracted from the wind or also called as power coefficient, $C_{p}$ of this kind of studied turbine has maximum power coefficient, $C_{p_{\max }}$ value of 0.4781 at tip speed ratio of 5.781. Tip speed ratio is the ratio between the peripheral blade speed, $\omega_{r} R$ and the wind speed, $U$.

The value of power coefficient $C_{p}$ is calculated by using Equation (1), whereas the tip speed ratio $\lambda$ is computed by using Equation (2). Equation (3) and (4) then are used to calculate the aerodynamic torque, $T_{\text {aero }}$ and aerodynamic power, $P_{\text {aero }}[2],[5]$.

$$
\begin{aligned}
& C_{p}=3.964305 e^{-5} \lambda^{6}-1.631763 e^{-3} \lambda^{5} \\
& +2.672766 e^{e-2} \lambda^{4}-2.201691 e^{-1} \lambda^{3} \\
& +9.253232 e^{-1} \lambda^{2}-1.702488 \lambda^{1}+1.136978
\end{aligned}
$$

$$
\begin{aligned}
& \lambda=\frac{\omega_{r} R}{U} \\
& T_{\text {aero }}=\frac{1}{2} \rho \pi R^{2} U^{3} \frac{C_{p}}{\omega_{r}} \\
& P_{\text {aero }}=\frac{1}{2} \rho \pi R^{2} C_{p} U^{3}
\end{aligned}
$$

Where $\omega_{r}=$ rotor speed, $R=$ blade radius, $U=$ wind speed, $\rho=$ air density.

\section{Drive Train Model}

Figure 3 represents the drive train model of wind turbine system. In the drive train model, the difference between low speed shaft and the high speed shaft is shown by the gearbox ratio.

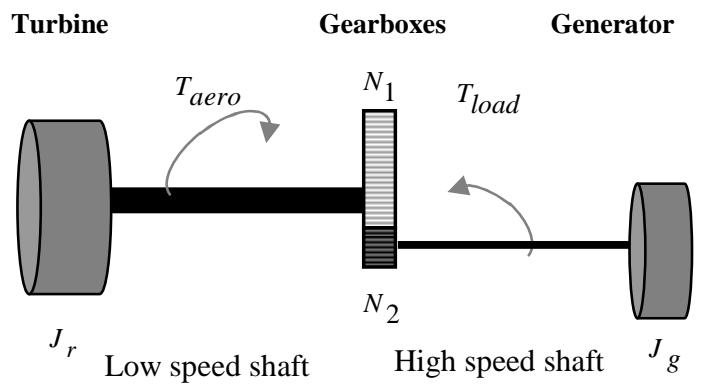

Figure 3: Drive train model

The drive train model is developed by using the simplest equation of motion to avoid the complex analysis where only rotational inertia is considered. The effects of damping and twisting angle of the shaft are ignored. In wind turbine system, unbalance torque occurs when turbine torque is dissimilar with the generator torque. As a result, shaft is accelerating or decelerating. The equation of motion for this rotation can be described as in Equation (5) [6]:

$$
\begin{gathered}
J \frac{d \omega_{m}}{d_{t}}=T_{\text {acc }}=T_{\text {aero }}-T_{\text {load }} \\
J=J_{r}+G^{2} J_{g} \quad, \quad G=\frac{\omega_{g}}{\omega_{m}}
\end{gathered}
$$

Where

$$
\begin{array}{ll}
J & =\text { moment of inertia of turbine and generator, } \\
& \mathrm{kgm}^{2} \\
\omega_{m} & =\text { Angular velocity of the rotor, } \mathrm{rad} / \mathrm{s} \\
t & =\text { Time, } \mathrm{s} \\
T_{\text {acc }} & =\text { Accelerating or decelerating torque, N.m } \\
T_{\text {aero }} & =\text { Aerodynamic torque, N.m } \\
T_{\text {load }} & =\text { Load torque or generator torque, N.m } \\
J_{r} & =\text { rotor inertia } \\
J_{g} & =\text { generator inertia } \\
G & =\text { gearbox ratio }
\end{array}
$$


The shaft will accelerate when $T_{\text {aero }}>T_{\text {load }}$, whereby the shaft decelerates when $T_{\text {aero }}<T_{\text {load }}$.

\section{Induction Generator Model}

Squirrel-cage induction generators are very popular and still widely used in industry for several reasons. Induction generators are definitely rugged, very reliable, brushless and economic. They also have a high capability to work under fast transient response. In fact they are able to work with excited programmable inverters or rectifiers. For variable speed operation, the existence of the full-scale frequency converter is very important in order to manipulate the advantages of matching speed to the changing load requirements during wind speed variations. This is the opposite of constant speed operation where capacitor bank and a soft-starter are needed to overcome the problem of poor reactive power control and for smoothing the grid connection, respectively [2]. Power generated from the machine is calculated by using Equation (6) while slip speed is calculated by using Equation (7):

$P_{g}=3 I_{2}{ }^{2} R_{2} \frac{(1-s)}{s}$

Where

$P_{g}=$ Generated power, $\quad s=\operatorname{slip}$

$I_{2}=$ Rotor current, $\quad I_{1}=$ Stator current

$R_{2}=$ Rotor resistance, $\quad R_{1}=$ Stator resistance

$X_{2}=$ Rotor reactance, $\quad X_{1}=$ Stator reactance

$X_{2}=$ Magnetizing reactance

Slip speed $=$ synchronous speed - rotor speed

\section{Closed-Loop Scalar Control}

The main objective of this paper is to keep the power at the rated value, $P_{\text {rated }}$. It is where the tip speed ratio operated between the optimum value, $\lambda_{\text {opt }}$ at 5.781 and $\lambda_{\min }$ at 2.408 , when wind speed reaches $12 \mathrm{~m} / \mathrm{s}$ up until $20 \mathrm{~m} / \mathrm{s}$. Then, from Equation (3) to (5), we can obtain the maximum power available in the wind is [1-3]

$$
P=\frac{1}{2} \rho \pi R^{5} C_{p \max } \frac{\omega_{r}^{3}}{\lambda_{o p t}{ }^{3}}
$$

An effective way to change the generator speed for squirrel cage induction generator wind turbine with fixed number of poles, is to change the frequency of the applied voltage. With this adjustable frequency drive, the fixed frequency supply voltage is able to convert to a continuous variable frequency, thereby allowing a proportional change in synchronous speed and rotor speed [6]. Equation (9) shows the relationship between flux, applied voltage and frequency of the machine.
$E_{1}=4.44 \Phi f N_{1}$

A closed-loop scalar control that was used to achieve this goal is shown in Figure 4 [7],[8]. From the figure, it shows that the generator speed, $\omega_{\mathrm{m}}$ which is measured by tachometer or encoder will be compared with the demanded generator speed, $\omega_{\mathrm{m} *}$. The demanded generator speed is obtained from the demanded (optimum) rotor speed, $\omega_{\mathrm{r} \_d e m}$ which is calculated by using Equation (2), when $\lambda$ vary between 2.408 or power coefficient vary from $C_{p_{\max }}$ at 0.4781 to $C_{p_{\min }}$ at 0.1032 . Then, the error of these speeds is entered into a PI controller. The result of PI control is the reference value of slip speed, $\omega_{\mathrm{sl}} *$ where this reference slip speed can be limited in the constant value even though the frequency and the voltage of the stator are varied. For the purpose of stability, it is necessary to ensure that the reference slip speed must be smaller than the critical slip speed. This is important because if the slip speed is larger than the critical slip speed, the current will become too large and hence will lead to overheat of the generator [9].

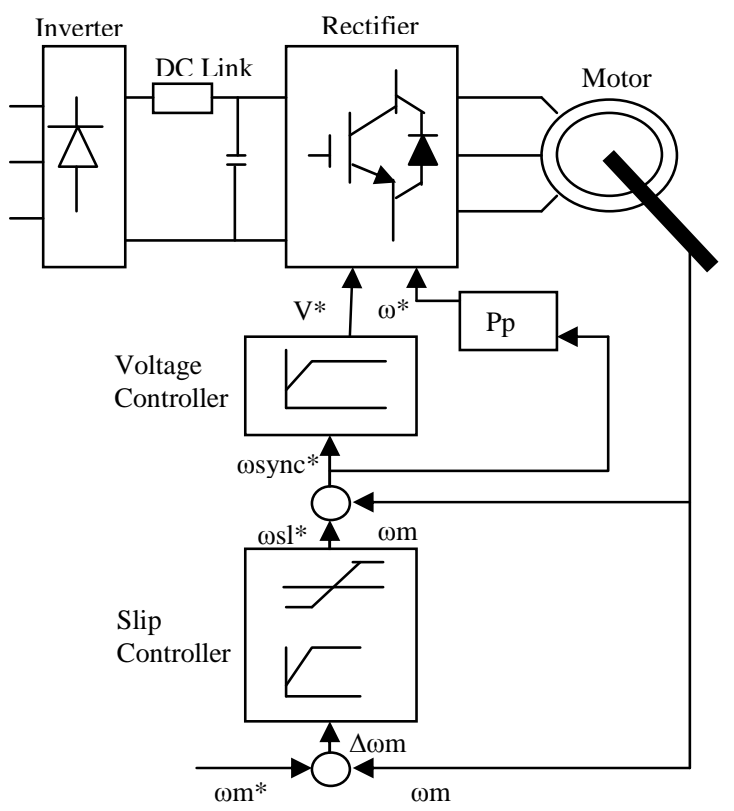

Figure 4: Scalar-controlled drive system with slip speed controller

Then, the estimated reference slip speed, $\omega_{\mathrm{sl}}{ }^{*}$ is added with the current value of the generator speed to calculate the new reference of synchronous speed, $\omega_{\text {synch* }}$.

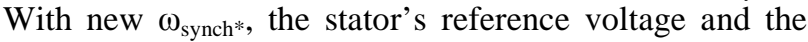
stator's reference frequency can be estimated. All mentioned speeds are in the unit of rad/s. These two variables are then fed into the generator side converter or also known as inverter. For variable speed drive, there are two types of inverter which is called as voltage source inverter (VSI) or current source inverter (CSI). VSI is more common used in the industry than the CSI [10]. By using VSI, the six-step or pulse width modulation (pwm) inverter can be used. However, the detail modeling of the inverter is not covered in this paper since this part concerns mostly in the grid interface side. 


\section{Simulation Results}

The characteristic of wind turbine which the simulations were performed is shown in Table I. These parameters correspond to the Carter turbine which located at West Beacon Farm, Loughborough. The Carter machine is 2-bladed and runs at fixed speed. It has fixed pitch regulated with a nominal power rating $25 \mathrm{~kW}$ and a hub height of $23.777 \mathrm{~m}$.

TABLE I. WIND TURBINE CHARACTERISTIC

\begin{tabular}{|l|l|}
\hline Blade rotor & $5 \mathrm{~m}$ \\
\hline Rotor inertia & $340.19 \mathrm{kgm}^{2}$ \\
\hline Generator inertia & $4.22 \mathrm{kgm}^{2}$ \\
\hline Air density & $1.225 \mathrm{~kg} / \mathrm{m}^{3}$ \\
\hline Gearbox Ratio & 12.748 \\
\hline Power output & $25 \mathrm{~kW}$ \\
\hline
\end{tabular}

Figure 5(a) represents the wind speed time series. From Figure 5(b) and (c), it can be seen that by using closed-loop scalar control with PI controller, the power coefficient can be reduced and the tip speed ratio can be controlled to be operated in the range between $\mathrm{Cp}_{\text {min }}, \lambda_{\text {min }}$ and $\mathrm{Cp}_{\mathrm{max}}, \lambda_{\mathrm{opt}}$. From the result in Figure $5(\mathrm{~d})$, the generated power can be kept at a constant value during the high wind speed fluctuations. However, there are several fluctuations from its rated value especially during wind speeds change from below rated wind speed to above rated wind speed region. The generator torque is shown in Figure 5(e). The torque works under permitted range.
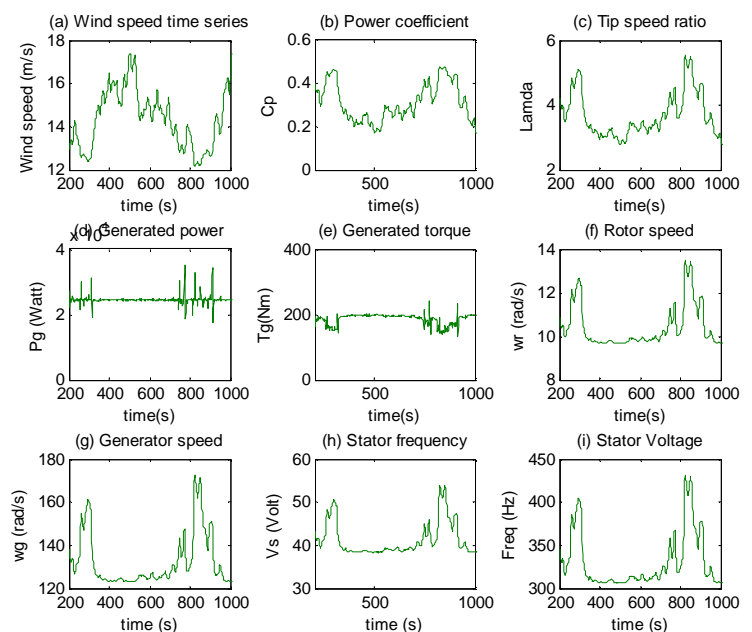

Figure 5: The results of (a) wind speed, (b) Power coefficient,

(c) Tip speed ratio, (d) Generated power (e) Demanded generator speed, (f) Demanded Torque, (g) Generator torque, (h) Rotor speed, (i) Generator speed.

By inspection of the results for the rotor speed and generator speed in Figure 5(f) and 5(g), it can be seen that the rotational speed changes in proportional to the wind speed variation. From the figure, it can be observed that the generator speed can vary between $79 \mathrm{rad} / \mathrm{s}$ to 158 $\mathrm{rad} / \mathrm{s}$ while the rotor speed may vary between $5.9 \mathrm{rad} / \mathrm{s}$ and $11.8 \mathrm{rad} / \mathrm{s}$ as expected. The results of generated stator frequency and stator voltage are depicted in Figure 5(h) and (i). The figure clearly shows that the stator voltage operates under rated voltage which is below 400 Volt. Stator frequency also works in the permitted range which is below $50 \mathrm{~Hz}$. The variations of rotor/generator speed, stator voltage and stator frequency show the impact of the variable speed concept.

\section{Conclusion}

This paper has investigated the use of Closed Loop Scalar Control for a variable speed stall regulated fixed pitch wind turbine in the stall region. The unstable dynamics of wind turbine system in this region has made effective control of excessive power and torque to be challenging. With the assistance of classical PI controllers in the slip and voltage loops, the slip speed can be limited at a permitted range where the slip speed is lower than the critical slip speed. As a consequence, by using this constant voltage/frequency (V/f) ratio of the generator's stator side control, the generator speed can be regulated and the generator torque can be controlled to ensure generated power can be maintained close to its rated value. As a result, generated power can be restricted at high (above rated) wind speeds. However, there are still significant excursions in power away from the rated power demanded when above rated wind speed. This may be due to inertias in the system and the fact that the controller is sub-optimal. These are topics of ongoing research.

\section{Acknowledgement}

The authors gratefully acknowledge the support of The Ministry of Higher Education (Malaysia) and Universiti Teknologi Malaysia (UTM) in funding this research.

\section{References}

[1] F.D. Bianchi, R.J. Mantz, H.D. Battista, Wind turbine control system: principles, modelling and gain Scheduling Design (London, Springer-Verlag, 2007).

[2] S. Heier, Grid integration of wind energy conversion systems (West Sussex, John Wiley \& Sons, Ltd, 2006).

[3] E. Muljadi, K. Pierce, P. Migliore, "Soft-stall control for variablespeed stall-regulated wind turbines," Journal of Wind Engineering and Industrial Aerodynamics, 85, 2000, 277-291.

[4] T. Ekelund, "Speed Control Wind Turbines in the Stall Region," Proceedings of the Third IEEE Conference on Control Applications, Vol.1, 1994.

[5] N.Rosmin, S.J.Watson, "Power Regulation at High Wind Speeds for a Variable Speed Stall-Regulated Wind Turbine," Proceedings of International Conference on Energy Efficiency \& Industrial Electronic Systems, Penang, Malaysia, Vol.1, 2009.

[6] P. Kundur, Power system stability and control (United States, McGraw Hill, Inc, 1993).

[7] N.Rosmin, S.J.Watson, M.Tompson "Speed Control at Low Wind Speeds for a Variable Speed Fixed Pitch Wind Turbine," Proceedings of Modelling, Identification \& Control, Innsbruck, Austria, February, 2010.

[8] R. Ramshaw and R.G. Van Heeswijk, Energy conversion electric motors and generators (United State of America, Saunders College publishing, 1990).

[9] A.M. Trzynadlowski, Control of induction motors (United State of America, Academic Press, 2001).

[10] B.K. Bose, Power electronics and variable frequency drives: Technology and Applications (United States of America, IEEE Press, 1997). 